\title{
A new theoretical calculation of the equilibrium constant and temperature for the carbon isotope exchange reaction between $\mathrm{CH}_{4}$ and $\mathrm{CO}_{2}$
}

\begin{abstract}
The equilibrium isotope fractionations among $\mathrm{C}-\mathrm{O}-\mathrm{H}$ gases in a variety of geological settings are commonly used as isotope geothermometers to evaluate the temperatures of geothermal fluids at depth, subsurface fluid-rock interactions, volcanic-hydrothermal systems and natural gas pools. However, due to limited experimental data and sophisticated theoretical calculations, applications of these geothermometers have been restricted. This study uses the carbon isotope exchange reaction between $\mathrm{CH}_{4}$ and $\mathrm{CO}_{2}$ as a case study to develop theoretical
\end{abstract} methods that can improve accuracies in calculating harmonic vibrational frequencies for $\mathrm{CH}_{4}$ and $\mathrm{CO}_{2}$, the equilibrium constants and temperatures for the carbon isotope exchange reaction between $\mathrm{CH}_{4}$ and $\mathrm{CO}_{2}$. Results suggest that the Bigeleisen-Mayer equation is sufficient to calculate the equilibrium constants and temperatures associated with the isotope exchange reaction between $\mathrm{CH}_{4}$ and $\mathrm{CO}_{2}$ with an accurate estimation of molecular harmonic vibrational frequencies. Calculations of the harmonic frequencies of $\mathrm{CH}_{4}$ and $\mathrm{CO}_{2}$ are achieved using the B3LYP density functional method with the $6-311+\mathrm{G}(\mathrm{d})$ basis set, and the calculated harmonic frequencies are highly consistent with experimental values. The frequency correction factor is taken as 1.022 which puts the calculated fractionation factors in good agreement with experimental values. The calculated equilibrium constants are comparable to experimental data and a theoretical data set. They are highly consistent. In order to improve the accuracy and efficiency for solving equilibrium temperatures using the Bigeleisen-Mayer equation, 
symbol operation and iterative algorithm in the MatLab software have been applied to compute the temperatures instead of using limited theoretical data sets or empirical fit equations. Our calculated results suggest that this algorithm can rapidly and conveniently yield relatively precise equilibrium temperatures. This algorithm can thus provide an important tool to evaluate whether the carbon isotope exchange reaction for $\mathrm{CH}_{4}$ and $\mathrm{CO}_{2}$ has attained equilibrium and estimate the formation temperature of $\mathrm{CH}_{4}$ and $\mathrm{CO}_{2}$ in high temperature geothermal systems.

Keywords: Isotope; Equilibrium fractionation; Temperature; New algorithm

\section{Introduction}

Stable isotope fractionation refers to mass dependent and/or mass independent effects, while the former is mainly controlled by kinetic isotope processes or equilibrium isotope effects, the latter may be associated with a photochemical process (Bigeleisen and Mayer, 1947; Clayton et al., 1973; Thiemens, 1999, 2006; Urey, 1947). The equilibrium isotope fractionations among C-O-H gases in a variety of geological settings are commonly used as isotope geothermometers to evaluate the temperatures of geothermal fluids at depth, subsurface fluid-rock interactions, volcanic-hydrothermal systems and natural gas pools (Chacko et al., 2001; Fiebig et al., 2004, 2013; Gherardi et al., 2005; Giggenbach, 1982, 1997; Schauble, 2004; Stolper et al., 2014, 2015; Wolfsberg et al., 2009). For example, the isotope 
geothermometers between the pairs $\mathrm{CO}_{2}-\mathrm{CH}_{4}, \mathrm{H}_{2} \mathrm{O}-\mathrm{H}_{2}, \mathrm{CO}_{2}-\mathrm{H}_{2} \mathrm{O}$ and $\mathrm{H}_{2}-\mathrm{CH}_{4}$ have been used to evaluate the temperatures at depth in active geothermal systems (Arnason, 1977; Gunter and Musgrave, 1971; Hulston, 1977; Panichi et al., 1977; Shangguan et al., 2006). However, there still exists much debate on the relative importance of equilibrium thermodynamic and kinetic processes in controlling the isotope compositions of geothermal gases even in high temperature geothermal systems (Fiebig et al., 2013; Gherardi et al., 2005; Giggenbach, 1997; Horita, 2001). This study uses the $\mathrm{CH}_{4}-\mathrm{CO}_{2}$ isotope geothermometer as a case study to further develop a theoretical calculation of the equilibrium constant and temperature for the carbon isotope exchange reaction between $\mathrm{CH}_{4}$ and $\mathrm{CO}_{2}$ in geothermal systems. Major reasons include (1) $\mathrm{CH}_{4}$ and $\mathrm{CO}_{2}$ are most probably in isotope equilibrium when they are formed together in high temperature geothermal systems (Fiebig et al., 2004, 2013; Panichi et al., 1977; Shangguan et al., 2006); (2) The $\mathrm{CH}_{4}-\mathrm{CO}_{2}$ isotope geothermometer can be used to estimate whether the isotope equilibrium between $\mathrm{CH}_{4}$ and $\mathrm{CO}_{2}$ has been reached, and if the equilibrium fractionation is obtained, the temperatures derived from this geothermometer could reflect the formation temperature of geothermal gases, at least the formation temperature of $\mathrm{CO}_{2}$ and $\mathrm{CH}_{4}$ (Panichi et al., 1977); (3) Most isotope geothermometers are based on a theoretical method proposed by Urey (1947) and Bigeleisen and Mayer (1947), however, the theoretical method is not sufficient to deal with H/D isotope exchange reactions (Liu et al., 2010; Urey, 1947). In general, the $\mathrm{CH}_{4}-\mathrm{CO}_{2}$ isotope geothermometer is a reliable tool for evaluating the temperatures of geothermal fluids at depth and plays an important role in geothermal exploration and risk assessment (Fiebig et al., 2013; Shangguan et al., 2006). Based on harmonic oscillator and rigid rotator models, Urey (1947) and Bigeleisen and 
Mayer (1947) proposed independently a theoretical method (e.g. Bigeleisen-Mayer equation) to estimate the equilibrium constants or temperatures for isotope exchange reactions. Since then, researchers have made corrections to the Bigeleisen-Mayer equation to improve accuracy of the theoretical evaluation of the equilibrium constants (Barone, 2005; Bigeleisen, 1996; Ellingson et al., 2007; Liu et al., 2010; Liu and Liu, 2016; Richet et al., 1977;

Wolfsberg et al., 1970). However, these corrections were mainly effective with respect to isotope exchange reactions in aqueous solutions or H/D isotope exchange (Wolfsberg et al., 1970). According to the Bigeleisen-Mayer equation, one of the most interesting characteristics of equilibrium isotope fractionation is that it only depends on temperature. The most important application of this characteristic is to determine the temperatures at which geological formations were laid down (Urey, 1947). However, it has been difficult to directly calculate the temperatures according the Bigeleisen-Mayer equation or other corrected equations due to their complexities. Thus researchers usually calculate the corresponding fractionation factors at different temperature values in the first place, then work out a relationship table or further apply this data to derive fit equations (such as, $10^{3} \ln \alpha=\mathrm{a}+\mathrm{b} / \mathrm{T}$; $10^{3} \ln \alpha=\mathrm{a}+\mathrm{b} / \mathrm{T}+\mathrm{c} / \mathrm{T}^{2}$ and $10^{3} \ln \alpha=\mathrm{a}+\mathrm{b} / \mathrm{T}+\mathrm{c} / \mathrm{T}^{2}+\mathrm{d} / \mathrm{T}^{3}$, etc., where $\mathrm{a}, \mathrm{b}, \mathrm{c}$ and $\mathrm{d}$ are constants, $\alpha$ and $\mathrm{T}$ are the equilibrium constant and temperature, respectively) to estimate the equilibrium temperatures (Bigeleisen and Mayer, 1947; Chacko et al., 2001; Horita, 2001; Richet et al., 1977; Stern et al., 1968). However, the calculated relationship data is extremely limited, and these fit equations cannot be extrapolated. They also significantly underestimate or overestimate fractionation factors or temperature values on many occasions (Horita, 2001; Richet et al., 1977). 
This study uses the carbon isotope exchange reaction between $\mathrm{CH}_{4}$ and $\mathrm{CO}_{2}$ as a case study. It focuses on developing methods that can improve accuracies and efficiencies in calculating harmonic vibrational frequencies for $\mathrm{CH}_{4}$ and $\mathrm{CO}_{2}$, the equilibrium constants and equilibrium temperatures for the isotope exchange reaction between $\mathrm{CH}_{4}$ and $\mathrm{CO}_{2}$. In addition, implications of the calculated temperature values are discussed.

\section{Theoretical method and results}

2.1 Theoretical method for equilibrium isotope fractionation between $\mathrm{CH}_{4}$ and $\mathrm{CO}_{2}$

A typical carbon isotope exchange reaction for $\mathrm{CH}_{4}$ and $\mathrm{CO}_{2}$ can be written as

$$
{ }^{12} \mathrm{CO}_{2}+{ }^{13} \mathrm{CH}_{4} \leftrightarrow{ }^{13} \mathrm{CO}_{2}+{ }^{12} \mathrm{CH}_{4}
$$

The equilibrium constant or fractionation factor $\alpha_{\mathrm{CO}_{2}-\mathrm{CH}_{4}}$ for this reaction is given as,

$\alpha_{\mathrm{CO}_{2}-\mathrm{CH}_{4}}=\frac{R_{\mathrm{CO}_{2}}}{R_{\mathrm{CH}_{4}}}=\frac{1000+\delta^{13} \mathrm{C}_{\mathrm{CO}_{2}}}{1000+\delta^{13} \mathrm{C}_{\mathrm{CH}_{4}}}=\left(\frac{q^{13} \mathrm{CO}_{2}}{q^{12} \mathrm{CO}_{2}}\right) /\left(\frac{q^{13} \mathrm{CH}_{4}}{q^{12} \mathrm{CH}_{4}}\right)$

where $q$ 's are the reduced partition functions of these molecules.

For carbon dioxide (linear) molecule,

$$
\frac{q_{13} \mathrm{CO}_{2}}{q^{{ }^{12} \mathrm{CO}_{2}}}=\prod_{1}^{3 N-5} \frac{u_{i}^{*}}{u_{i}} \frac{e^{-u_{i}^{*} / 2}\left(1-e^{-u_{i}}\right)}{e^{-u_{i} / 2}\left(1-e^{-u_{i}^{*}}\right)}
$$

and for methane (non-linear) molecule,

$$
\frac{q^{{ }^{13} \mathrm{CH}_{4}}}{{ }_{{ }^{12} \mathrm{CH}_{4}}}=\prod_{1}^{3 N-6} \frac{u_{i}^{*}}{u_{i}} \frac{e^{-u_{i}^{*} / 2}\left(1-e^{-u_{i}}\right)}{e^{-u_{i} / 2}\left(1-e^{-u_{i}^{*}}\right)}
$$

where $3 N-5(6)$ stands for the amount of normal vibration of the $N$-atomic molecule, 
$u_{i}=\frac{h c \omega_{i}}{k T}, u_{i}^{*}=\frac{h c \omega_{i}^{*}}{k T}, h$ is the Planck constant, $c$ is the speed of light, $\omega_{i}$ and $\omega_{i}^{*}$ are the harmonic frequency of normal mode $i$ for light and heavy isotopic molecule respectively, $k$ is the Boltzmann constant, and $T$ is the temperature (Bigeleisen and Mayer, 1947; Urey, 1947; Wolfsberg et al., 2009).

\subsection{Calculated results}

\subsubsection{Harmonic frequencies}

Based on equations (1)-(3), fractionation factors can be calculated for given temperature values if the molecular harmonic frequencies are known. In this study, the harmonic frequency calculations for $\mathrm{CH}_{4}$ and $\mathrm{CO}_{2}$ were performed using Gaussian 09 and GaussView 5 software (Frisch et al., 2009). Gaussian 09 is based on fundamental laws of quantum mechanics and can be used to predict molecular structures, vibrational frequencies and energies. GaussView 5 is a graphical interface used in conjunction with Gaussian 09. It helps the creation of Gaussian input files and the interpretation of Gaussian output. Several variants of density functional theory (DFT) (such as B-LYP, B3-LYP, B3-P86, and B3-PW91) with the 3-21G, 6-31+G(d), 6-311G(d, p), and 6-311G(df, p) basis sets are widely used to calculate harmonic vibrational frequencies in the Gaussian software (Frisch et al., 2009; Scott and Radom, 1996). Of various hybrid DFT methods, the B3LYP functional has been widely used (Andersson and Uvdal, 2005; Scott and Radom, 1996). Therefore, this study used the B3LYP method combined with the $6-311+\mathrm{G}(\mathrm{d})$ basis set for the calculations of geometry 
optimizations and harmonic vibrational frequencies.

The theoretical harmonic frequencies calculated for $\mathrm{CH}_{4}$ and $\mathrm{CO}_{2}$ molecules, such as ${ }^{12} \mathrm{CH}_{4},{ }^{13} \mathrm{CH}_{4},{ }^{12} \mathrm{CO}_{2}$ and ${ }^{13} \mathrm{CO}_{2}$, are given in Table 1 . These values are compared with the experimental data from previous studies (Gray and Robiette, 1979; Lee et al., 1995; Pariseau et al., 1965) to check the accuracy of the calculation. In Table 1 , the $\Delta_{\omega}\left(\omega_{2}-\omega_{3}\right)$ values for $\mathrm{CH}_{4}$ are between $-4.75 \mathrm{~cm}^{-1}$ and $21.79 \mathrm{~cm}^{-1}$, the $\Delta_{\omega}\left(\omega_{1}-\omega_{3}\right)$ values for $\mathrm{CO}_{2}$ are between -23.94 $\mathrm{cm}^{-1}$ and $4.54 \mathrm{~cm}^{-1}$. Fig .1 shows that the calculated and experimental values plot along a line with the slope of $\sim 1.00$ and intercept of $\sim 0.00$. This reflects that the calculated harmonic vibrational frequencies are in close agreement with experimental values for these molecules $\left({ }^{12} \mathrm{CH}_{4},{ }^{13} \mathrm{CH}_{4},{ }^{12} \mathrm{CO}_{2}\right.$ and $\left.{ }^{13} \mathrm{CO}_{2}\right)$, although minor differences still exist (Table 1, Fig. 1).

\section{Table 1}

Calculated theoretical harmonic frequencies, experimental values and multiplicity of degenerate frequencies.

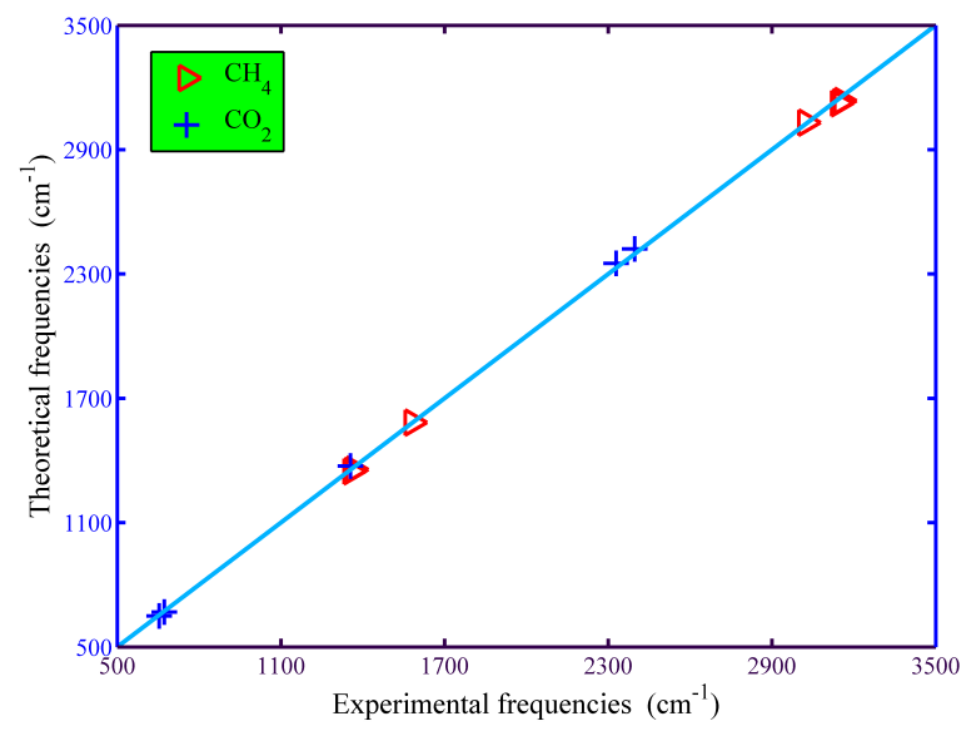


Fig. 1. Theoretical harmonic vibrational frequencies versus experimental frequencies of methane and carbon dioxide. The experimental frequencies of methane are harmonic, while the frequencies of carbon dioxide are from a direct experimental observation (the frequency data are all from Table 1).

\subsubsection{Equilibrium constants}

In this study the calculated harmonic vibrational frequencies for $\mathrm{CH}_{4}$ and $\mathrm{CO}_{2}$ have been corrected and the correction factor is taken to be 1.022 which makes the calculated equilibrium constants close to the experimental values provided by Horita (2001). Table 2 lists the calculated equilibrium constants, experiment values and errors. The results show that the error range of $\beta_{1}-\beta_{2}$ is between -0.3223 and 0.4948 . Fig. 2 compares the calculated equilibrium constants with the experimental values by Horita (2001). Table 3 and Fig. 3 compare the equilibrium constants calculated in this study with the data sets calculated by Richet et al. (1977). Table 3 shows the error range of $\gamma_{1}-\gamma_{2}$ is from -0.0022 to -0.0002 . We find that the equilibrium constants calculated in this study using the correction factor are in good agreement with experimental and calculated results from previous studies.

\section{Table 2}

Calculated fractionation factors (expressed in $10^{3} \ln \alpha_{\mathrm{CO}_{2}-\mathrm{CH} 4}$ ) between $200.6^{\circ} \mathrm{C}$ and $550.0^{\circ} \mathrm{C}$ in this study and experimental values from Horita (2001).

\section{Table 3}

Isotope fractionation factors (expressed as $\left.\ln \alpha_{\mathrm{CO}_{2}-\mathrm{CH}_{4}}\right)$ calculated in this study $\left(\gamma_{2}\right)$ between $0^{\circ} \mathrm{C}$ and $1300^{\circ} \mathrm{C}$ and calculated by Richet et al. (1977) $\left(\gamma_{1}\right)$. 


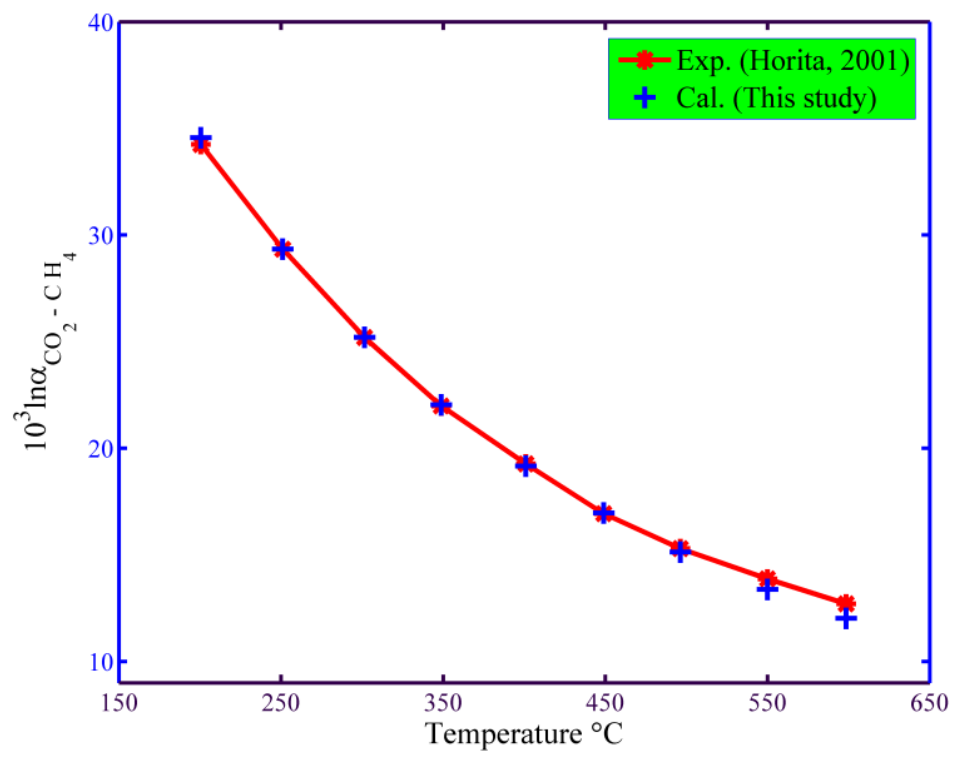

Fig. 2. Plot of the calculated equilibrium constants in this study (expressed as $10^{3} \ln \alpha_{\mathrm{CO}_{2}-\mathrm{CH}_{4}}$ ) between $200^{\circ} \mathrm{C}$ and $600^{\circ} \mathrm{C}$ versus experimental values by Horita (2001).

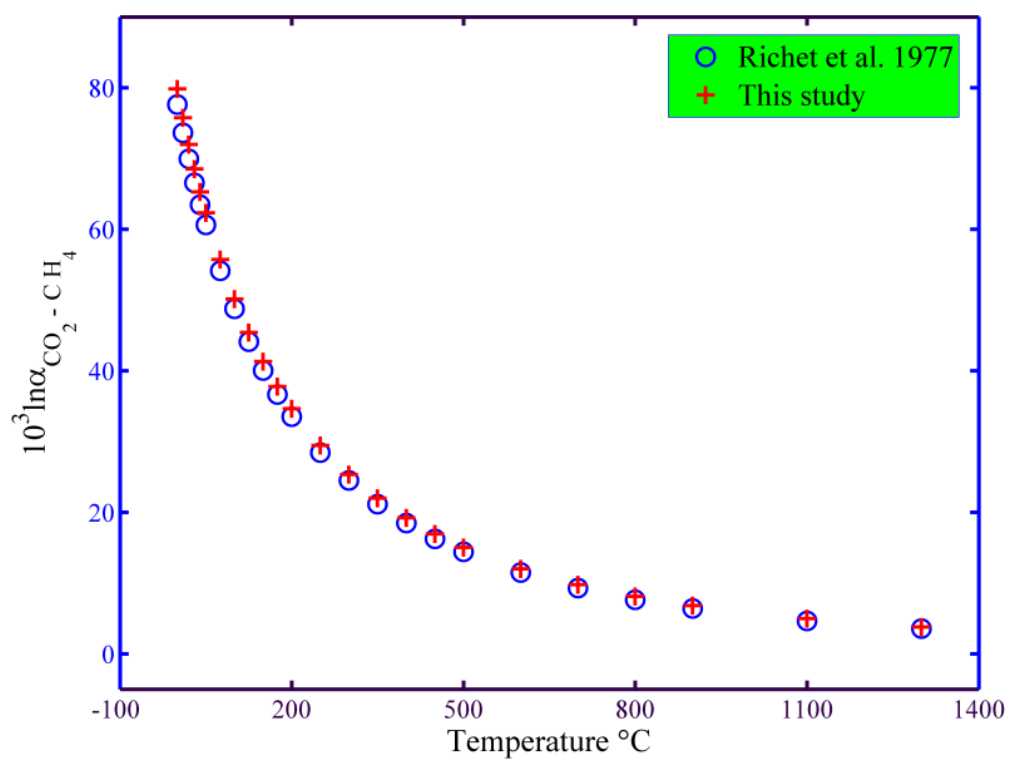

Fig. 3. Plot of calculated equilibrium constants in this study (expressed as $10^{3} \ln \alpha_{\mathrm{CO}_{2}-\mathrm{CH}_{4}}$ ) from $0^{\circ} \mathrm{C}$ to $1300^{\circ} \mathrm{C}$ versus calculated values by Richet et al. (1977).

\subsubsection{Equilibrium temperatures}


Equilibrium temperatures are calculated directly according to equation (1) instead of using limited data sets or empirical fit equations. The symbol operation and iterative algorithm in the MatLab software are applied for calculations (Supplementary Information). The algorithm

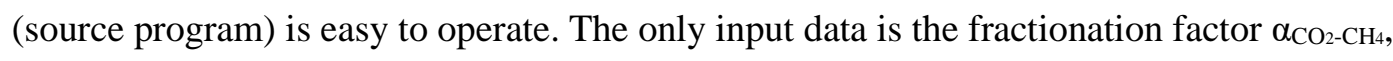
and then the corresponding equilibrium temperature can be calculated within one minute. Table 4 shows an exact set of temperature values, the corresponding fractionation factors, and the calculated temperature values. The results show that absolute errors associated with temperature values are less than $2^{\circ} \mathrm{C}$.

\section{Table 4}

Comparison of calculated temperatures and exact values for different fractionation factors.

\section{Discussion}

In the Bigeleisen-Mayer equation, molecular vibrational frequencies should be pure harmonic frequencies, and they can be obtained either theoretically or via experiments. In general, it is not easy to obtain pure harmonic frequencies from experimental spectroscopic data, particularly for polyatomic molecules and isotopically substituted molecules (Liu et al., 2010). However, the DFT methods can be used easily to calculate pure harmonic frequencies (Andersson and Uvdal, 2005; Scott and Radom, 1996). In this study, we use the B3LYP functional method with the $6-311+\mathrm{G}(\mathrm{d})$ basis set to calculate vibrational frequencies for $\mathrm{CH}_{4}$ and $\mathrm{CO}_{2}$. The calculated frequencies are comparable to the experimental observed and harmonic ones (Table 1, Fig. 1). Our calculated results are highly consistent with 
experimental values, especially for ${ }^{12} \mathrm{CH}_{4}$ and ${ }^{13} \mathrm{CH}_{4}$. This agreement suggests that the B3LYP method with the $6-311+\mathrm{G}(\mathrm{d})$ basis set is very reliable and can be used to precisely estimate the harmonic frequencies for some molecules and their isotopocules.

Our calculated equilibrium constants (Table 2, Table 3, Fig. 2 and Fig. 3) are in good agreement with experimental and calculated values from previous studies (Horita, 2001; Richet et al., 1977), suggesting that applying the Bigeleisen-Mayer equation can achieve relatively precise equilibrium constants if molecular harmonic frequencies are estimated with high accuracy. Table 2 and Fig. 2 compare the calculated equilibrium constants with the experimental results (Horita, 2001), the results indicate that our calculated equilibrium constants are very accurate. Table 3 and Fig. 3 compare the equilibrium constants calculated in this study with the presumably more accurate data sets (Richet et al., 1977) which were attained from a complicated corrected Bigeleisen-Mayer equation, the results suggest that two different methods can yield highly consistent fractionation factors and the higher the temperature, the better consistency it can achieve. Therefore, under the condition that fractionation factor $\alpha_{\mathrm{CO}_{2}-\mathrm{CH}_{4}}$ is given, the relatively simple equation (1) can be used to compute the equilibrium temperature precisely.

To improve the accuracy and efficiency of solving equations to obtain equilibrium temperatures using equation (1), the symbol operation and iterative algorithm in the MatLab software are applied to compute the temperature values instead of using limited data sets or empirical fit equations. This algorithm can be used to calculate the corresponding equilibrium temperature if the input fractionation factor is between 1.08309 and 1.00086 (Table 4). In other words, the equilibrium temperatures should be in the range between $0^{\circ} \mathrm{C}$ and $3000^{\circ} \mathrm{C}$ for 
the $\mathrm{CH}_{4}-\mathrm{CO}_{2}$ isotope geothermometer. The set absolute errors associated with temperature calculations are less than $2^{\circ} \mathrm{C}$. Although small differences still exist $\left(<2^{\circ} \mathrm{C}\right)$ between the calculated values and the exact solutions, our results suggest that they are generally in good agreement (Table 4). If it is necessary, the differences can be reduced by resetting the error range. In principle, by resetting the range of the temperature values, this algorithm can be applied to calculate any corresponding equilibrium temperature under any condition that the fractionation factor is given.

Based on the discussion above, we find that the harmonic frequencies and equilibrium constants calculated in this study are reliable and accurate by comparison with experimental and theoretical data from previous studies. This suggests that the relatively simple equation (1) compared with the theoretical method provided by Richet et al. (1977) is more suitable for dealing with equilibrium carbon isotope fractionation between $\mathrm{CH}_{4}$ and $\mathrm{CO}_{2}$. Furthermore, it has been difficult to calculate the equilibrium temperatures by directly applying the Bigeleisen-Mayer equation or the theoretical method provided by Richet et al. (1977), our algorithm can solve this problem very well, and can conveniently and rapidly calculate relatively precise equilibrium temperatures using the Bigeleisen-Mayer equation.

\section{Implications}

Investigations on the isotope composition of carbon dioxide and methane from geothermal fluids, hot springs, coal seams and shale rocks have been carried out for many years. However, there has been an ongoing debate on the relative importance of kinetics and equilibrium in 
controlling their isotope distribution (Fiebig et al., 2004, 2013; Gherardi et al., 2005;

Giggenbach, 1997; Panichi et al., 1977; Stolper et al., 2014, 2015; Tao et al., 2007, 2015).

Our algorithm (source program) is an important tool in evaluating whether the carbon isotope exchange reaction for $\mathrm{CH}_{4}$ and $\mathrm{CO}_{2}$ has attained equilibrium. Because our algorithm can conveniently and rapidly calculate relatively precise corresponding equilibrium temperature under the condition that fractionation factor $\alpha_{\mathrm{CO}_{2}-\mathrm{CH}_{4}}$ is known. The "equilibrium" temperature associated with other geothermal parameters can then be used to estimate whether the isotope equilibrium between $\mathrm{CH}_{4}$ and $\mathrm{CO}_{2}$ has been reached.

The formation temperatures of $\mathrm{CH}_{4}$ and $\mathrm{CO}_{2}$ are very important in geothermal exploration and risk assessment. However, they are often poorly constrained in nature (Fiebig et al., 2013; Panichi et al., 1977; Stolper et al., 2014). Some researchers have assumed that $\mathrm{CH}_{4}$ and $\mathrm{CO}_{2}$ were most probably in isotope equilibrium when they were formed together in active high temperature geothermal systems (Fiebig et al., 2013; Gherardi et al., 2005; Panichi et al., 1977; Shangguan et al., 2006). For example, Panichi et al. (1977) applied the $\mathrm{CH}_{4}-\mathrm{CO}_{2}$ isotope geothermometer to study the formation temperature of geothermal gases in the Larderello geothermal field. They suggested that temperatures derived from the isotope geothermometer reflected the formation temperature of $\mathrm{CO}_{2}$ and $\mathrm{CH}_{4}$ and that the temperatures actually existed in the geothermal fields. If this hypothesis on isotope equilibrium fractionation was correct, and $\mathrm{CO}_{2}$ and/or $\mathrm{CH}_{4}$ from other sources were not added, the formation temperatures of $\mathrm{CO}_{2}$ and $\mathrm{CH}_{4}$ could be calculated accurately by applying our algorithm. Furthermore, the depth where they were formed together could be estimated. 


\section{Conclusions}

The harmonic frequency calculations for $\mathrm{CH}_{4}$ and $\mathrm{CO}_{2}$ were performed using Gaussian 09 and GaussView 5, and the theoretical method was chosen as the B3LYP density functional method with the 6-311+G(d) basis set. The calculated frequencies are in close agreement with experimental values for the molecules ${ }^{12} \mathrm{CH}_{4},{ }^{13} \mathrm{CH}_{4},{ }^{12} \mathrm{CO}_{2}$ and ${ }^{13} \mathrm{CO}_{2}$. The frequency correction factor is taken to be 1.022 which makes the calculated fractionation factors closely approach experimental values provided by Horita (2001). Equilibrium constants are calculated for the isotope exchange reaction between $\mathrm{CH}_{4}$ and $\mathrm{CO}_{2}$ using equation (1). And the calculated equilibrium constants are in good agreement with the experimental values (Horita, 2001) and the theoretically calculated data sets (Richet et al., 1977). The results suggest that the equation (1) is more suitable for dealing with equilibrium carbon isotope fractionation between $\mathrm{CH}_{4}$ and $\mathrm{CO}_{2}$. In order to improve the accuracy and efficiency of solving for equilibrium temperatures using equation (1), a new algorithm (e.g. symbol operation and iterative algorithm in the MatLab software) is used to compute the temperatures according to equation (1) instead of using limited experimental and calculated data sets or empirical fit equations. In this algorithm, the set temperature ranges between $0^{\circ} \mathrm{C}$ and $3000^{\circ} \mathrm{C}$, and the set absolute error is less than $2^{\circ} \mathrm{C}$. The new algorithm (source program) has wide applications in geothermal exploration and associated risk assessment.

\section{Acknowledgements}

The authors acknowledge Yun Liu and Shuguang Li for their helpful lectures. This work was 
supported by National Natural Science Foundation of China (Grants 41472102 and 41772122). This paper has been greatly improved by detailed comments and helpful suggestions from editor Dr. (put name(s) here) and three anonymous reviewers.

\section{Supplementary Information}

The source program applied to compute the equilibrium temperature is provided in the

Supporting file.

\section{References}

Andersson, M.P., Uvdal, P., 2005. New scale factors for harmonic vibrational frequencies using the B3LYP density functional method with the triple- $\zeta$ basis set 6-311+G(d, p). J. Phys. Chem. 109, 2937-2941.

Arnason, B., 1977. The hydrogen-water isotope thermometer applied to geothermal areas in Iceland. Geothermics 5, 75-80.

Barone, V., 2005. Anharmonic vibrational properties by a fully automated second-order perturbative approach. J. Chem. Phys. 122, 014108.

Bigeleisen, J., 1996. Nuclear size and shape effects in chemical reactions. Isotope chemistry of the heavy elements. J. Am. Chem. Soc. 118, 3676-3680.

Bigeleisen, J., Mayer, M.G., 1947. Calculation of equilibrium constants for isotopic exchange reactions. J. Chem. Phys. 15, 261-267.

Chacko T., Cole, D.R., Horita, J., 2001. Equilibrium Oxygen, Hydrogen and Carbon Isotope Fractionation Factors Applicable to Geologic Systems. Rev. Mineral. Geochemistry 43, 1-81.

Clayton, R. N., Grossman, L., Mayeda, T. K., 1973. A component of primitive nuclear composition in carbonaceous meteorites. Science 182, 485-488. 
Ellingson, B.A., Pu, J., Lin, H., Zhao, Y., Truhlar, D.G., 2007. Multicoefficient Gaussian-3 calculation of the rate constant for the $\mathrm{OH}+\mathrm{CH}_{4}$ reaction and its ${ }^{12} \mathrm{C} /{ }^{13} \mathrm{C}$ kinetic isotope effect with emphasis on the effects of coordinate system and torsional treatment. J. Phys. Chem. A 111, 11706-11717.

Fiebig, J., Chiodini, G., Caliro, S., Rizzo, A., Spangenberg, J., Hunziker, J.C., 2004. Chemical and isotopic equilibrium between $\mathrm{CO}_{2}$ and $\mathrm{CH}_{4}$ in fumarolic gas discharges: generation of $\mathrm{CH}_{4}$ in $\operatorname{arc}$ magmatic-hydrothermal systems. Geochim. Cosmochim. Acta 68, 2321-2334.

Fiebig, J., Tassi, F., D'Alessandro, W., Vaselli, O., Woodland, A.B., 2013. Carbon-bearing gas geothermometers for volcanic-hydrothermal systems. Chem. Geol. 351, 66-75.

Frisch, M.J., Trucks, G.W., Schlegel, H.B., Scuseria, G.E., Robb, M.A., Cheeseman, J.R., Scalmani, G., Barone, V., Mennucci, B., Petersson, G.A., Gaussian 09, revision A.02; Gaussian Inc.: Wallingford CT, 2009.

Gherardi, F., Panichi, C., Gonfiantini, R., Magro, G., Scandiffio, G., 2005. Isotope systematics of C-bearing gas compounds in the geothermal fluids of Larderello, Italy. Geothermics 34, 442-470.

Giggenbach, W. F., 1982. Carbon-13 exchange between $\mathrm{CO}_{2}$ and $\mathrm{CH}_{4}$ under geothermal conditions. Geochim. Cosmochim. Acta 46 159-165.

Giggenbach W. F., 1997. Relative importance of thermodynamic and kinetic processes in governing the chemical and isotopic composition of carbon gases in high-heatflow sedimentary basins. Geochim. Cosmochim. Acta 61, 3763-3785.

Gray, D.L., Robiette, A.G., 1979. The anharmonic force field and equilibrium structure of methane. Mol. Phys. 37, 1901-1920.

Gunter, B.D., Musgrave, B.C., 1971. New evidence on the origin of methane in hydrothermal gases. Geochim. Cosmochim. Acta 35, 113-118.

Horita, J., 2001. Carbon isotope exchange in the system $\mathrm{CO}_{2}-\mathrm{CH}_{4}$ at elevated temperatures. Geochim. Cosmochim. Acta 65, 1907-1919.

Hulston, J.R., 1977. Isotope work applied to geothermal systems at the Institute of Nuclear Sciences, New Zealand. Geothermics 5, 89-96.

Lee, T.J., Martin, J.M.L., Taylor, P.R., 1995. An accurate ab initio quartic force field and vibrational frequencies for $\mathrm{CH}_{4}$ and isotopomers. J. Chem. Phys. 102, 254-261.

Liu, Q., Liu, Y., 2016. Clumped-isotope signatures at equilibrium of $\mathrm{CH}_{4}, \mathrm{NH}_{3}, \mathrm{H}_{2} \mathrm{O}, \mathrm{H}_{2} \mathrm{~S}$ and $\mathrm{SO}_{2}$. Geochim. Cosmochim. Acta 175, 252-270. 
Liu, Q., Tossell, J. A., Liu, Y., 2010. On the proper use of the Bigeleisen-Mayer equation and corrections to it in the calculation of isotopic fractionation equilibrium constants. Geochim. Cosmochim. Acta 74, 6965-6983.

Panichi, C., Ferrara, G.C., Gonfiantini, R., 1977. Isotope geothermometry in the Larderello geothermal field. Geothermics 5, 81-88.

Pariseau, M.A., Suzuki, I., Overend, J., 1965. Least-Squares Adjustment of Anharmonic Potential Constants: Application to ${ }^{12} \mathrm{CO}_{2}$ and ${ }^{13} \mathrm{CO}_{2}$. J. Chem. Phys. 42, 2335-2344.

Richet, P., Bottinga, Y., Janoy, M., 1977. A review of hydrogen, carbon, nitrogen, oxygen, sulphur and chlorine stable isotope enrichment among gaseous molecules. Ann. Rev. Earth Planet. Sci. 5, 65-110.

Schauble, E.A., 2004. Applying stable isotope fractionation theory to new systems. Rev. Mineral. Geochemistry 55, 65-111.

Scott, A.P., Radom, L., 1996. Harmonic Vibrational Frequencies: An Evaluation of Hartree-Fock, Møller-Plesset, Quadratic Configuration Interaction, Density Functional Theory, and Semiempirical Scale Factors. J. Phys. Chem. 100, 16502-16513.

Shangguan, Z., Zhao, C., Gao, L., 2006. Carbon isotopic compositions of the methane derived from magma at the active volcanic regions in China. Acta. Petrol Sin. 22, 1458-1446 (in Chinese).

Stern, M.J., Spindel, W., Monse, E.U., 1968. Temperature dependences of isotope effects. J. Chem. Phys. 48, 2908-2919.

Stolper, D.A., Lawson, M., Davis, C.L., Ferreira, A.A., Neto, E.S., Ellis, G.S., Sessions, A.L., 2014. Formation temperatures of thermogenic and biogenic methane. Science 344, 1500-1503.

Stolper, D.A., Martini, A.M., Clog, M., Douglas, P.M., Shusta, S.S., Valentine, D.L., Eiler, J.M., 2015. Distinguishing and understanding thermogenic and biogenic sources of methane using multiply substituted isotopologues. Geochim. Cosmochim. Acta 161, 219-247.

Tao, M., Ma, Y., Li, Z., Li, J., Liu, P., Wang, Y., Chen, X., Zhang, A., 2015. The Isotopic Tracer and Resource Value of Microbial Gas Production in Coalbeds-A Case Study of Coalbed Gas in Enhong, China. Energy \& Fuels 29, 2134-2142.

Tao, M., Shi, B., Li, J., Wang, W., Li, X., Gao, B., 2007. Secondary biological coalbed gas in the Xinji area, Anhui province, China: evidence from the geochemical features and secondary changes. Int. J. Coal Geol. 71, 358-70. 
Thiemens, M.H., 1999. Mass-independent isotope effects in planetary atmospheres and the early solar system. Science 283, 341-345.

Thiemens, M. H., 2006. History and Applications of Mass-Independent Isotope Effects. Earth Planet. Sci. 34, 217-262.

Urey, H.C., 1947. The thermodynamic properties of isotopic substances. J. Chem. Soc. (Lond.), 562-581.

Wolfsberg, M., Massa, A.A., Pyper, J.W., 1970. Effect of Vibrational Anharmonicity on the Isotopic Self-Exchange Equilibria $\mathrm{H}_{2} \mathrm{X}+\mathrm{D}_{2} \mathrm{X}=2 \mathrm{HDX}$. J. Chem. Phys. 53, 3138-3146.

Wolfsberg, M., Van Hook, W.A., Paneth, P., Rebelo, L.P.N., 2009. Isotope Effects: in the chemical, geological, and bio sciences. Springer Science \& Business Media, New York.

\section{Tables}

\section{Table 1}

Calculated theoretical harmonic frequencies, experimental values and multiplicity of degenerate frequencies.

\begin{tabular}{|c|c|c|c|c|c|}
\hline & \multicolumn{2}{|c|}{ Experimental $^{\mathrm{a}}$} & \multirow{2}{*}{$\begin{array}{l}\text { Theoretical } \\
\text { Harmonic } \omega_{3}\end{array}$} & \multirow{2}{*}{$\begin{array}{c}\text { Difference }^{\mathrm{b}} \\
\Delta_{\omega}\end{array}$} & \multirow{2}{*}{ Degeneracy } \\
\hline & Observed $\omega_{1}$ & Harmonic $\omega_{2}$ & & & \\
\hline \multirow{4}{*}{${ }^{12} \mathrm{CH}_{4}$} & 2916.5 & 3025.5 & 3030.25 & -4.75 & 1 \\
\hline & 1533.3 & 1582.7 & 1582.64 & 0.06 & 2 \\
\hline & 3019.2 & 3156.8 & 3135.06 & 21.74 & 3 \\
\hline & 1310.8 & 1367.4 & 1355.13 & 12.27 & 3 \\
\hline \multirow{4}{*}{${ }^{13} \mathrm{CH}_{4}$} & 2915.4 & 3025.5 & 3030.25 & -4.75 & 1 \\
\hline & -- & 1582.7 & 1582.64 & 0.06 & 2 \\
\hline & 3009.5 & 3145.6 & 3123.81 & 21.79 & 3 \\
\hline & 1302.8 & 1358.9 & 1346.75 & 12.15 & 3 \\
\hline \multirow{3}{*}{${ }^{12} \mathrm{CO}_{2}$} & 1354.91 & -- & 1373.18 & -18.27 & 1 \\
\hline & 673.00 & -- & 668.46 & 4.54 & 2 \\
\hline & 2396.49 & -- & 2420.43 & -23.94 & 1 \\
\hline \multirow{3}{*}{${ }^{13} \mathrm{CO}_{2}$} & 1354.91 & -- & 1373.18 & -18.27 & 1 \\
\hline & 653.83 & -- & 649.44 & 4.39 & 2 \\
\hline & 2328.22 & -- & 2351.54 & -23.32 & 1 \\
\hline
\end{tabular}

${ }^{a}$ Experimental vibrational frequencies for methane are from Lee et al. (1995) and Gray and Robiette (1979); for carbon dioxide are from Pariseau et al. (1965). 
${ }^{\mathrm{b}}$ The difference values $\Delta_{\omega}$ for methane and carbon dioxide were obtained from $\omega_{2}-\omega_{3}$ and $\omega_{1}-\omega_{3}$, respectively. The symbol '--' denotes that the data is not collected.

\section{Table 2}

Calculated fractionation factors (expressed in $10^{3} \ln \alpha_{\mathrm{CO}_{2-\mathrm{CH}} \text { ) }}$ between $200.6^{\circ} \mathrm{C}$ and $550.0^{\circ} \mathrm{C}$ in this study and experimental values from Horita (2001).

\begin{tabular}{cccc}
\hline \multirow{2}{*}{$\begin{array}{c}\text { Temperature } \\
\left({ }^{\circ} \mathrm{C}\right)\end{array}$} & \multicolumn{2}{c}{$10^{3} \ln \alpha_{\mathrm{CO} 2-\mathrm{CH} 4}$} & \multirow{2}{*}{\begin{tabular}{c} 
Error \\
\cline { 2 - 3 }
\end{tabular}} \\
\cline { 2 - 3 } 200.6000 & 34.2400 & $\beta_{1}-\beta_{2}$ \\
\hline 251.1000 & 29.3300 & 34.5623 & -0.3223 \\
301.5000 & 25.1900 & 29.3412 & -0.0112 \\
348.8000 & 21.9800 & 25.2008 & -0.0108 \\
401.0000 & 19.2600 & 22.0370 & -0.0570 \\
449.0000 & 16.9300 & 19.1629 & 0.0971 \\
496.3000 & 15.2900 & 16.9664 & -0.0364 \\
550.0000 & 13.8700 & 15.1341 & 0.1559 \\
\hline
\end{tabular}

\section{Table 3}

Isotope fractionation factors (expressed as $\left.\ln \alpha_{\mathrm{CO}_{2}-\mathrm{CH}_{4}}\right)$ calculated in this study $\left(\gamma_{2}\right)$ between $0^{\circ} \mathrm{C}$ and $1300^{\circ} \mathrm{C}$ and calculated by Richet et al. (1977) $\left(\gamma_{1}\right)$.

\begin{tabular}{|c|c|c|c|}
\hline \multirow{2}{*}{$\begin{array}{l}\text { Temperature } \\
\left({ }^{\circ} \mathrm{C}\right)\end{array}$} & \multicolumn{2}{|c|}{$\ln \alpha_{\mathrm{CO} 2-\mathrm{CH} 4}$} & \multirow{2}{*}{$\begin{array}{l}\text { Error } \\
\gamma_{1}-\gamma_{2}\end{array}$} \\
\hline & $\gamma_{1}$ & $\gamma_{2}$ & \\
\hline 0 & 0.0776 & 0.0798 & -0.0022 \\
\hline 10 & 0.0736 & 0.0757 & -0.0021 \\
\hline 20 & 0.0700 & 0.0720 & -0.0020 \\
\hline 30 & 0.0666 & 0.0685 & -0.0019 \\
\hline 40 & 0.0634 & 0.0653 & -0.0019 \\
\hline 50 & 0.0606 & 0.0623 & -0.0017 \\
\hline 75 & 0.0541 & 0.0557 & -0.0016 \\
\hline 100 & 0.0488 & 0.0501 & -0.0013 \\
\hline 150 & 0.0400 & 0.0413 & -0.0013 \\
\hline 200 & 0.0335 & 0.0346 & -0.0011 \\
\hline 250 & 0.0284 & 0.0294 & -0.0010 \\
\hline 300 & 0.0245 & 0.0253 & -0.0008 \\
\hline 350 & 0.0211 & 0.0219 & -0.0008 \\
\hline 400 & 0.0185 & 0.0192 & -0.0007 \\
\hline 450 & 0.0163 & 0.0169 & -0.0006 \\
\hline 500 & 0.0144 & 0.0150 & -0.0006 \\
\hline 600 & 0.0115 & 0.0120 & -0.0005 \\
\hline 700 & 0.0093 & 0.0098 & -0.0005 \\
\hline 800 & 0.0076 & 0.0081 & -0.0005 \\
\hline 1100 & 0.0046 & 0.0050 & -0.0004 \\
\hline
\end{tabular}




\begin{tabular}{llll}
\hline 1300 & 0.0036 & 0.0038 & -0.0002 \\
\hline
\end{tabular}

\section{Table 4}

Comparison of calculated temperatures and exact values for different fractionation factors.

\begin{tabular}{ccc}
\hline & \multicolumn{2}{c}{ Temperature $\left.^{\circ}{ }^{\circ} \mathrm{C}\right)$} \\
\cline { 2 - 3 } & Exac-CH4 & Calculated values \\
\hline 1.0831 & 0 & 0 \\
1.0573 & 75.0 & 75 \\
1.0421 & 150.6 & 150 \\
1.0256 & 300.9 & 300 \\
1.0151 & 500.5 & 500 \\
1.0098 & 700.7 & 701 \\
1.0068 & 900.4 & 901 \\
1.00298 & 1500.6 & 1501 \\
1.001803 & 2000.8 & 2001 \\
1.000865 & 2999.3 & 2999 \\
\hline
\end{tabular}

${ }^{\mathrm{c}}$ The exact value is a given value that is used to calculate the corresponding fractionation factor according to equation (1). 